\title{
The polyene macrolide antibiotics
}

\author{
D. KERRIDGE \\ M.A., Ph.D.

\begin{abstract}
Sub-department of Chemical Microbiology, Department of Biochemistry, Tennis Court Road, Cambridge CB2 1QW
\end{abstract}

\begin{abstract}
Summary
The mode of action of the polyene antibiotics is reviewed together with the effect of genetic and environmental factors on sensitive organisms. The future prospects of polyenes in the treatment of systemic mycoses are considered.
\end{abstract}

THE effective treatment of any infection requires at least one significant difference between host and parasite to provide a target for the chemotherapeutic agent. Fungi, like their human hosts, are eukaryotes and the differences which could provide a target are limited and occur largely in the cell envelope. Numerous antifungal antibiotics have been isolated but most are toxic and few are used clinically. The polyene macrolide antibiotics comprise a complex group of some 200 compounds produced by various Streptomyces spp. of which only amphotericin B is sufficiently non-toxic to be used to treat systemic mycoses. Chemically these compounds are characterized by a carbon ring possessing both a system of conjugated double bonds and a hydrophilic region and closed by a lactone bond. Polyenes differ in the number of carbon atoms in the ring, the number of conjugated double bonds and the number of hydroxyl residues (Hamilton-Miller, 1973; Cartwright, 1975; Thomas, 1976; Norman, Spielvogel and Wong, 1976; Kobayashi and Medoff, 1977). The complete structure of amphotericin B has been elucidated by Mechlinski et al. (1970) and this antibiotic is an elongated rigid molecule with opposing hydrophobic and hydrophilic faces, features of undoubted importance in its biological activity.

The polyenes interact with sterol-containing membranes of eukaryotic organisms causing impairment of function and ultimately cell death; prokaryotic organisms, other than sterol-containing Acholeplasma spp. and Mycoplasma spp., are unaffected (Lampen, 1966). The extent of membrane damage depends both on the lipid composition (in particular the sterols) of the membrane and the antibiotic (Norman et al., 1976). In general, polyenes with a lower molecular weight cause more damage than those with a higher molecular weight. The differences in the affinities of polyenes for cholesterol-containing mammalian membranes and ergosterol-containing fungal membranes make it possible to use certain of these antibiotics in the chemotherapy of mycotic infections (Gale, 1973; Archer and Gale, 1975).

The mechanisms by which individual polyenes interact with the membranes of sensitive cells may differ from one polyene to another. In the case of amphotericin B (a heptaene) and nystatin (a tetraene) data, derived largely from in vitro experiments with artificial membranes, support the hypothesis that incorporation of the polyene into the membrane results in the production of aqueous pores consisting of an annulus of polyene and sterol in which the hydrophilic region of the polyene faces the interior of the pore. The length of the annulus is such that 2 half pores would appear necessary to span the membrane (De Kruijff and Demel, 1974; Andreoli, 1973; Holz, 1974). Marty and Finkelstein (1975) have proposed a modification where either a single or double annulus can span the bilayer in each case with distortion in the vicinity of the polyene. This model may help to explain the production of pores in the membranes where the antibiotic is added to the outside of sensitive organisms. The polyenemembrane interaction is reversible both in vitro (Holz, 1974) and in vivo (Cass and Dalmark, 1973; Kumar et al., 1974; Liras and Lampen, 1974; Kerridge, Koh and Johnson, 1976 a) and the inhibitory effects would appear to result from the loss of $\mathrm{K}^{+}$ions and other low molecular weight constituents (Lampen, 1966). This hypothesis is supported by the findings that for Saccharomyces cerevisiae (Liras and Lampen, 1974) and Candida albicans (Kerridge et al., 1976 b) the inhibitory effects of candicidin and amphotericin $B$ respectively are prevented by the concomitant addition of $\mathrm{K}^{+}$and $\mathrm{Mg}^{++}$.

However, this hypothesis requires revision in the light of recent experimental findings. In vitro studies by Hsu-Chen and Feingold (1973) and in vivo studies by Archer (1976) have provided evidence 
that the membrane fluidity is of primary importance and the presence of the sterol modulates this fluidity. Polyene-induced $\mathrm{K}^{+}$leakage has been widely used as a measure of the interaction of the antibiotic with sensitive organisms (Hammond and Kliger, 1974; Gale, 1974; Johnson, White and Williamson, 1978) but there is evidence that the loss of intracellular $\mathrm{K}^{+}$may not be responsible for cell death. Polyeneresistant mutants of $C$. albicans have been isolated in which polyene-induced leakage of low molecular weight cellular constituents occurs under conditions where there is no loss of viability (Hsu-Chen and Feingold, 1974). Hammond, Lambert and Kliger (1974) and more recently Chen, Chou and Feingold (1978) have demonstrated a dissociation of $\mathrm{K}^{+}$ion permeability and the lethal action of the polyene antibiotics and the latter authors suggest that the aqueous pores formed by these antibiotics are not central to their lethal action. Further evidence that $\mathrm{K}+$ leakage may not be directly responsible for the loss of viability comes from studies by Palacios and Serrano (1978) on the amphotericin B inhibition of maltose fermentation in $S$. cerevisiae where they demonstrated a polyene-induced increase in proton permeability. Since $\mathrm{K}^{+}$accumulation in yeast is linked to the proton gradient (Pena, 1975) this could account for the polyene induced $\mathrm{K}+$ leakage (see also Hugo, 1978). Finally Solov'eva, Belousova and Tereshin (1976) have shown an inhibitory effect of polyenes on the activity of certain membrane-bound enzymes of $C$. albicans, but the relationship of this to the loss of viability is not clear.

The interaction of polyenes with sensitive organisms is affected by genetic and environmental factors. Amphotericin B may have severe side effects when administered and the maximum concentration attainable in the serum is of the order of $1-3 \mu \mathrm{g} / \mathrm{ml}$. In a study of clinical isolates of $C$. albicans, Hamilton-Miller (1972) found that $17 \%$ of them were not inhibited by amphotericin $\mathbf{B}$ at concentrations normally found in serum and it is clear from these data that even small variations in the sensitivity of these organisms could be clinically important. The occurrence of amphotericin-resistant mutants of C. albicans is not a serious clinical problem and most studies of genetically mediated resistance have been undertaken with mutagen-treated cultures. In these strains, resistance appears to be associated with an alteration in the membrane sterols resulting from a block in ergosterol biosynthesis and an increase in the total sterol content (Pierce et al., 1978). It is interesting to note that in this context Virina et al. (1976) found no differences in the binding of amphotericin B to polyene-sensitive and to resistant strains of $C$. albicans.

The interaction of amphotericin B with C. albicans is influenced by a variety of environmental factors.
The addition of sterols together with the polyene can reduce its effect on the growth of $C$. albicans (Archer and Gale, 1975) and this apparent increase in the minimum growth inhibitory concentration results from the lowering of the effective concentration due to an in vitro interaction between the polyene and lipid (Bittman and Fishkoff, 1972; Norman et al. 1972). The presence of lipids in the growth medium also affects the composition of the cellular membranes of an oleic acid-requiring strain of $C$. albicans and, as a result, the sensitivity of this organism to inhibition by amphotericin B (Koh et al., 1977). The inhibitory effects of certain polyenes can also be prevented by the concomitant addition of $\mathrm{K}^{+}$and $\mathrm{Mg}^{++}$(Liras and Lampen, 1974; Kerridge et al., $1976 \mathrm{a}$ ). In this case the antibiotic interacts with the plasma membrane but the internal concentration of ions is maintained and growth continues.

Phenotype variation in C. albicans also affects the antibiotic sensitivity of this organism; not only are there changes in the sensitivity to amphotericin B after the cessation of growth (Hammond and Kliger, 1974; Gale, 1974) but also in cultures grown in continuous culture under different environmentalo conditions (Johnson et al., 1978). In these studies, polyene-mediated $\mathrm{K}^{+}$release was used to monitor sensitivity to polyenes but since the authors usedo different techniques the results are not directly comparable. After the cessation of growth of $C$. albicans the organism becomes increasingly resistant to amphotericin B methyl ester. This increased resistance results from changes in the cell wall since sphaeroplasts derived from resistant organisms are sensitive (Gale, 1974). The development of resistance is affected by a variety of factors including complexity and $\mathrm{pH}$ value of the growth medium, degree of aeration and presence of metabolic inhibitors (Gale, Johnson and Kerridge, 1977; Gale et al., 1975, 1978). The sensitivity of the organism can also be altered by chemical or enzymatic treatment of the cell wall. Ultrastructural studies of the cell wall of $C$. albicans have shown that after $72 \mathrm{hr}$ 's starvation, when resistance to amphotericin B methyl ester had increased some 60 -fold, both the characteristic layering and the periplasmic material were lost. There was however no change in thickness of the wall at this stage although after $144 \mathrm{hr}$ the wall had increased in thickness to $211 \pm 58 \mathrm{~nm}$ from the initial value of $143 \pm 22 \mathrm{~nm}$ (Cassone, Kerridge and Gale, 1978). Although there are considerable changes in the ultrastructure of the cell wall on starvation it has not been possible to detect any significant differences in composition of the cell walls isolated from resistant and sensitive cultures (Kerridge et al., 1976 b), but this might be due to loss of material during preparation (Cassone et al., 
1978). However, given the complexity of the cell wall of $C$. albicans and the size and shape of the polyene molecule it is perhaps not surprising that even small variations in structure and organization of the cell wall can profoundly affect the interaction of the antibiotic with the underlying plasma membrane.

What are the future prospects for polyenes in the treatment of systemic mycoses? the major problem is that we are dealing with a eukaryotic pathogen in a eukaryotic host and differences between them reside largely in the cell envelope, with the pathogen having a complex cell wall surrounding an ergosterolcontaining plasma membrane and the host having a cholesterol-containing membrane with no cell wall. These features are important in both the selectivity and the development of antibiotic resistance in the pathogen; and clearly one possibility for the future would be to search for new polyenes or derivatives of existing ones with a greater affinity for ergosterolcontaining membranes (and preferably fewer side reactions) and whose activity is less affected by the phenotypic changes which can occur in the cell wall. Polyenes are large, complex and unstable molecules and the probability of a successful chemical or biosynthetic modification low. However, there has been one notable success in the synthesis of the methyl ester of amphotericin B (Mechlinski and Schaffner, 1972; Chen et al., 1977) where methylation has increased the apparent solubility and reduced toxicity without reducing the antifungal activity, and clearly this approach must be pursued.

\section{References}

ANDREOLI, T.E. (1973) On the anatomy of amphotericin Bcholesterol pores in lipid bilayer membranes. Kidney International, 4, 337.

ARCHER, D.B. (1976) Effect of the lipid composition of Mycoplasma mycoides subspecies capri and phosphatidylcholine vesicles upon the action of polyene antibiotics. Biochimica et biophysica acta, 436, 68.

ARCher, D.B. \& GALE, E.F. (1975) Antagonism by sterols of the action of amphotericin and filipin on the release of potassium ions from Candida albicans and Mycoplasma mycoides subsp. capri. Journal of General Microbiology, 90, 187.

Bittman, R. \& Fischkoff, S.A. (1972) Fluorescent studies of the binding of the polyene antibiotics filipin III, amphotericin B, nystatin and lagosin to cholesterol. Proceedings of the National Academy of Sciences of the United States of America, 69, 3795.

Cass, A. \& Dalmark, M. (1973) Equilibrium dialysis of ions in nystatin-treated red cells. Nature. London, 224, 47.

Cassone, A., Kerridge, D. \& Gale, E.F. (1979) Ultrastructural changes in the cell wall of Candida albicans following the cessation of growth and their possible relationship to the development of polyene resistance. Journal of General Microbiology, 110, 339.

Cartwright, R.Y. (1975) Antifungal drugs. Journal of Antimicrobial Chemotherapy, 1, 141.

Chen, C.C., Chou, D.-L. \& FeIngold, D.S. (1978) Dissociation between ion permeability and the lethal action of polyene antibiotics on Candida albicans. Antimicrobial Agents and Chemotherapy, 13, 914.

Chen, W.C., Sud, I.J., Chou, D.-L. \& Feingold, D.S. (1977) Selective toxicity of the polyene antibiotics and their methyl ester derivatives. Biochemical and Biophysical Research Communications, 74, 480.

De KruijfF, B. \& Demel, R.A. (1974) Polyene antibioticsterol interactions in membranes of Acholeplasma laidlawii cells and lecithin liposomes. III. Molecular structures of the polyene antibiotic complexes. Biochimica et biophysica acta, 339, 57.

GALE, E.F. (1973) Perspectives in chemotherapy. British Medical Journal, 4, 33.

GALE, E.F. (1974) The release of potassium ions from Candida albicans in the presence of polyene antibiotics. Journal of General Microbiology, 80, 451.

Gale, E.F., Johnson, A.M. \& KerRidge, D. (1977) The effect of aeration 'and metabolic inhibitors on resistance to amphotericin in starved cultures of Candida albicans. Journal of General Microbiology, 99, 77.

Gale, E.F., Johnson, A.M., KerRidge, D. \& KoH, T.Y. (1975) Factors affecting the changes in amphotericin sensitivity during growth. Journal of General Microbiology 87, 20.

Gale, E.F., Johnson, A.M., Kerridge, D. \& Miles, E.A. (1978) Phenotypic resistance to amphotericin in Candida albicans; the role of reduction. Journal of General Microbiology, 109, 191.

HAMILTON-MILlER, J.M.T. (1972) A comparative in vitro study of amphotericin B, clotrimazole and 5-fluorocytosine against clinically isolated yeasts. Sabouraudia, 10, 276.

Hamilton-Miller, J.M.T. (1973) Chemistry and biology of the polyene macrolide antibiotics. Bacteriological Reviews, 37, 166.

Hammond, S.M. \& Kliger, B.N. (1974) Studies on the role of the cell wall of Candida albicans in the mode of action of polyene antibiotics. Proceedings of the Society for General Microbiology, 1, 45.

Hammond, S.M., Lambert, P.A. \& Kliger, B.N. (1973) The mode of action of polyene antibiotics; induced potassium leakage in Candida albicans. Journal of General Microbiology, 81, 325.

Holz, R.W. (1974) The effects of the polyene antibiotics nystatin and amphotericin B on thin lipid membranes. Annals of the New York Academy of Sciences, 235, 469.

Hsu-Chen, C.C. \& Feingold, D.S. (1973) Polyene action on lecithin liposomes; effect of cholesterol and fatty acyl chains. Biochemical and Biophysical Research Communications, 51, 972.

Hsu-Chen, C.C. \& Feingold, D.S. (1974) Two types of resistance to antibiotics in Candida albicans. Nature. London, 251, 656.

Hugo, W.B. (1978) Membrane-active antimicrobial drugs. A reappraisal of their mode of action in the light of the chemiosmotic theory. International Journal of Pharmacology, 1, 127.

Johnson, B., White, R.J. \& Williamson, G.M. (1978) Factors affecting the susceptibility of Candida albicans to the polyenoic antibiotics nystatin and amphotericin $B$. Journal of General Microbiology, 104, 325.

Kerridge, D., KoH, T.Y. \& Johnson, A.M. (1976a) The interaction of amphotericin B methyl ester with protoplasts of Candida albicans. Journal of General Microbiology, 96, 117.

Kerridgf, D., Koh, T.Y., Marriott, M.S. \& Gale, E.F. (1976b) The production and properties of protoplasts from the dimorphic yeast Candida albicans. In: Microbial and Plant Protoplasts (Ed. by Peberdy, J.F., Rose, A.H., Rogers, H.J. \& Cocking, E.C.), p. 23. Academic Press, New York. 
Kobayashi, G.S. \& Medoff, G. (1977) Antifungal agents: Recent developments. Annual Reviews of Microbiology, 31, 291.

Koh, T.Y., Marriott, M.S., TAYlor, J. \& Gale, E.F. (1977) Growth characteristics and polyene sensitivity of a fatty acid auxotroph of Candida albicans. Journal of General Microbiology, 102, 105.

Kumar, B.V., MedofF, G., KobaYASHI, G.S. \& Schlessinger, D. (1974) Uptake of Eschicheria coli DNA into HeLa cells enhanced by amphotericin B. Nature. London, 256, 323.

LAMPEN, J.O. (1966) Interference by polyene antibiotics (especially nystatin and filipin) with specific membrane functions. Symposia of the Society for General Microbiology, 16, 111.

LiRAS, P. \& LAMPEN, J.O. (1974) Protection by $\mathrm{K}^{+}$and $\mathrm{Mg}^{++}$ of growth and macromolecular synthesis in candicidintreated yeast. Biochimica et biophysica acta, 374, 159.

Marty, A. \& Finkelstein, A. (1975) Pores formed in lipid bilayer membranes by nystatin. Differences in the onesided and two-sided action. Journal of General Physiology, 65, 515.

Mechlinski, W. \& Schaffner, C.B. (1972) Polyene macrolide derivatives. $\mathbf{I}$. $\mathbf{N}$-acylation and esterification reactions with amphotericin B. Journal of Antibiotics. Tokyo, 25, 256.

Mechlinksi, W., Schaffner, C.P., Ganis, P. \& Avitabile, G. (1970) Structure and absolute configuration of the polyene macrolide antibiotic amphotericin B. Tetrahedron Letters, No. 44, 3873.

Norman, A.W., Demel, R.A., De Kruyff, B., Geurts van Kessel, W.S. \& VAN Deenen, L.L.M. (1972) Studies on the biological properties of polyene antibiotics: comparison of other polyenes with filipin in their ability to interact specifically with sterol. Biochimica et biophysica acta, $290,1$.

Norman, A.W., Spielvogel, A.M. \& Wong, R.G. (1976) Polyene antibiotic-sterol interaction. In: Advances in Lipid $\subseteq$ Research (Ed. by Paoletti, R. \& Kritchecski, D.), vol. 14.

Palacios, J. \& Serrano, R. (1978) Proton permeability $\stackrel{\oplus}{\rightarrow}$ induced by polyene antibiotics. A plausible mechanism for $\bar{O}$ their inhibition of maltose fermentation in yeast. FEBS Letters, 91, 198.

Pena, A. (1975) Studies on the mechanism of $\mathbf{K}^{+}$transport in yeast. Archives of Biochemistry and Biophysics, 167, 397.

Pierce, A.M., Pierce Jr, H.D., UnRaU, A.M. \& OehlschlaGER, A.C. (1978) Lipid composition and polyene resistance $\mathscr{C}$ of Candida albicans mutants. Canadian Journal of Bio- $\vec{O}$ chemistry, 56, 135.

Solov'eva, N.N., Belousova, I.I. \& Tereshin, I.M. (1976) [Influence of the polyene antibiotics on the lactate dehydrogenase and ATPase activity of the membrane fraction of Candida albicans.] Khimiko-Farmatsevticheskii Zhurnal, $10,18$.

Thomas, A.H. (1976) Analysis and assay of polyene anti- ن fungal antibiotics. A review. Analyst, 101, 321.

Virina, A.M., Feisin, A.M., Fateeva, L.I., Kasumov, Kh.M., Belousova, L.L. \& Tereshin, I.M. (1976) [Inter- . action of polyene antibiotics with sensitive and resistant strains of Candida albicans.] Khimiko-Farmatsevticheskii Zhurnal, 10, 12. 